\title{
Reclosing scheme using synchronism checking for utilization of BESS in distribution system
}

\author{
Hun-Chul SEO ${ }^{1}$, Sang-Bong RHEE ${ }^{2}$
}

MPCE

\begin{abstract}
This paper proposes a reclosing scheme using synchronism checking for utilization of battery energy storage system (BESS) in a distribution system. The algorithm disconnects the faulty phase and keeps the power supply from the BESS to the healthy phase. Synchronism checking between the main source side and the load side is applied to minimize the transients at the reclosing instant. The BESS at the faulty phase is reconnected after checking the successful reclosing. The distribution system including BESS and proposed reclosing scheme are modeled by the electromagnetic transients program (EMTP)/ATPDraw. The various simulations by varing the fault clearing time are conducted and the simulation results are discussed. Also, the relation between proposed reclosing scheme and reliability is discussed.
\end{abstract}

Keywords Distribution system, Battery energy storage system (BESS), Reclosing, Reliability, Synchronism checking

CrossCheck date: 15 November 2017

Received: 10 June 2017/Accepted: 15 November 2017/Published online: 20 December 2017

(C) The Author(s) 2017. This article is an open access publication

Sang-Bong RHEE

rrsd@yu.ac.kr

Hun-Chul SEO

hunchu10119@hanmail.net

1 School of IT Engineering, Yonam Institue of Technology, Jinju, Korea

2 Department of Electrical Engineering, Yeungnam University, Gyeongsan, Korea

\section{Introduction}

All of the worlds are trying to make a smart grid. To advance the establishment of smart grid, the power distribution systems with a battery energy storage system (BESS) should be increased. To accomplish these, several studies on the grid connection of the large-capacity BESS have been performed. Most of these studies have focused on the operation and control strategy of the BESS for the integration with renewable energy, energy management, power quality, and etc. [1-13]. However, few protection studies in power systems with BESSs have been performed. Therefore, this paper deals with a reclosing issues among the protection issues in the distribution system.

The operation of BESS during fault depends on its purpose of use and hence the effects of BESS on the reclosing are also different. To utilize the BESS for frequency regulation and peak load shaving, a distribution system must be operated at a steady state $[14,15]$. The reclosing scheme considering BESS used for these purposes in the distribution system were discussed in [16]. If the BESS is connected during fault and serves the power to a healthy phase, the interruption will be prevented by the uninterrupted power supply (UPS). In this case, the distribution system is exposed to the new challenges in reclosing procedure because the BESS maintains the power service to a healthy phase even at fault conditions. New challenges not considered in conventional reclosing of distribution system are listed below $[14,15]$.

1) Detection of a faulty phase. The BESS in a faulty phase must be disconnected from the distribution system to prevent the fault current contribution, and it must only be connected in a healthy phase.

2) Installation of circuit breaker (CB) at each phase for connecting of BESS. 
3) Synchronism problem between main source side (utility power) and load side (power from the BESS) in reclosing operation. The synchronism problem is not considered in conventional reclosing in a distribution system. However, a reclosing in distribution system that serves the power from BESS to a healthy phase is similar with reclosing of a transmission system, and so the synchronism problem must be considered.

4) Reconnection of the BESS in a faulty phase after successful reclosing. The BESS in a faulty phase must be reconnected to the distribution system after successful reclosing in order to charge the BESS for operation as a UPS under the next fault conditions.

This paper proposes the reclosing scheme using synchronism in the distribution system with the BESS used as UPS. The proposed technique is based on dead time in conventional reclosing scheme. Section 2 presents the newly proposed reclosing technique that considers the BESS, including the system configuration for the proposed technique and the flow chart for the algorithm. Section 3 describes the simulation performed using the electromagnetic transients program (EMTP)/ATPDraw and EMTP models, along with the simulation conditions and results that verify the proposed reclosing technique. Finally, conclusions derived from our study are discussed in Section 4.

\section{New reclosing technique considering BESS}

\subsection{System configuration of proposed reclosing technique}

This paper proposes a reclosing technique when the BESS is used as UPS. Figure 1 shows the system configuration for the proposed reclosing technique with the BESS. The inputs of protective relay are the current $i_{1-}$ $(t)$ and voltage $v_{1}(t)$ from the system, and the voltage $v_{2}(t)$ at the BESS. The outputs of protective relay according to the proposed algorithm are an open/close signal for both

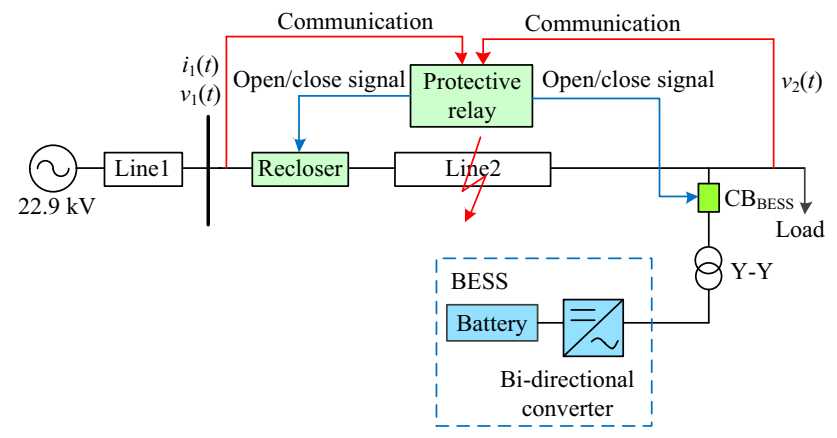

Fig. 1 System configuration of new reclosing technique the recloser at main distribution line and the $\mathrm{CB}_{\mathrm{BESS}}$ for selecting connection /disconnection of BESS, as shown in Fig. 1. As the most of recloser installed in distribution system, the recloser in Fig. 1 performs the open/close operation of three phase. However, because the BESS at faulted phase must be disconnected from the distribution system and the one at healthy phase maintains the power supply, $\mathrm{CB}_{\mathrm{BESS}}$ in Fig. 1 must perform the separate open/close operation at each phase. In other words, $\mathrm{CB}_{\mathrm{BESS}}$ which has single phase operating mechanism must be installed at each phase. Because the BESS is located far from recloser in most of cases, the proper and fast communication skill is required for successful sending and receiving of input and output signal in proposed reclosing procedure.

For high voltage connection of BESS, the diverse cases exist. In [17], the BESS is connected to the $12.5 \mathrm{kV}$ distribution system through $240 \mathrm{~V} / 12.5 \mathrm{kV}$ transformer. In $[18,19]$, the BESS is connected to the $24.9 \mathrm{kV}$ distribution system. Reference [12] describes the demonstration project of China. The State Grid Corporation of China (SGCC) is building the national wind/PV/BESS and transmission joint demonstration project and it is located in the region of Zhangbei, Hebei, China. The demonstration project is scheduled in three stages. Now, it is in the first stage and at the end of December, 2011, a $100 \mathrm{MW}$ wind farm, a 40 MW PV farm, and 14 MW/63 MWh lithium-ion BESS have been built at Zhangbei [12]. In this project, the BESS is connected to the high voltage power grid via transformer. In Korea, the field test of BESS has been performed at Jocheon substation, Jeju. The BESS is connected to the $154 \mathrm{kV}$ high voltage system via bi-directional converter and transformer. The common point of these researches is the BESS is connected to the high voltage power system through bi-directional converter and transformer.

Therefore, we design the BESS system, which is composed of battery, bi-directional converter, and transformer, for the connection to the $22.9 \mathrm{kV}$ distribution system. A Liion battery, which is sufficient for improving power quality and power system reliability, is adopted. The bi-directional AC-DC converter works as the interface between the battery and the ac grid. BESS supplies the power via $380 \mathrm{~V} /$ $22.9 \mathrm{kV}$ Y-Y transformer to the distribution system to prevent voltage swell at healthy phase during fault $[14,15]$.

The grounding method used in the distribution system is a solid grounding. This is a common grounding mode used in most distribution system of Korea. If the resistance or arc suppression coil grounding are used, the fault cannot be detected by current amplitude change because the fault current depends on the resistance or coil values. Therefore, the proposed algorithm cannot be applied. 


\subsection{Flowchart of proposed reclosing technique}

Figure 2 presents a flow chart of the proposed reclosing technique in the distribution system with the BESS for UPS. The inputs for the reclosing technique are the current $i_{1}(t)$ and voltage $v_{1}(t)$ from the system, and the voltage $v_{2}(t)$ at the BESS connection point. In normal state, the proposed technique calculates the amplitude, phase angle, and frequency. When a fault occurs $\left(I_{1 \mathrm{~A}}\right.$ or $I_{1 \mathrm{~B}}$ or $\left.I_{1 \mathrm{C}}>\alpha\right)$, the recloser is opened. In this step, a faulty phase is instantly detected by amplitude variation of current at each phase. If the current from system at any phase is bigger than $\alpha$, it is judged as the faulty phase and hence the trip

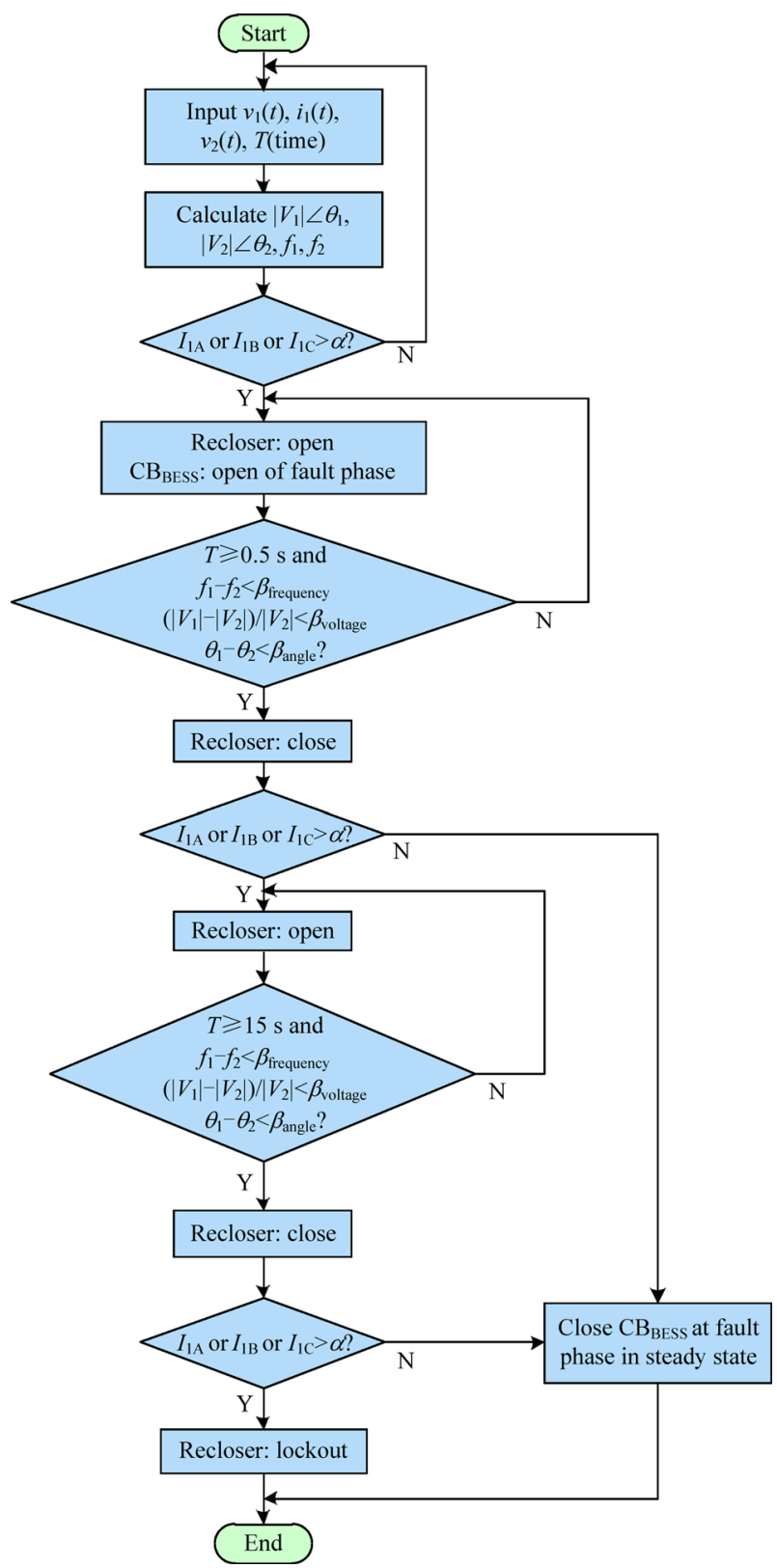

signal of $\mathrm{CB}_{\mathrm{BESS}}$ at faulty phase is sent to disconnect the BESS at faulty phase from distribution system. The first reclosing is attempted when the fixed dead time $(0.5 \mathrm{~s})$ in conventional reclosing has elapsed and the synchronism checking has been completed.

The items of synchronism checking are the differences in frequency, phase angle, and voltage amplitude between the utility power and the power from the BESS. If the reclosing is successful, the BESS in a faulty phase is reconnected to the distribution system after checking the voltage and frequency in the steady state. If the reclosing fails, the recloser is re-opened. A second reclosing is attempted when the fixed dead time (15 s) in conventional reclosing has elapsed and the synchronism checking has been completed. If the second reclosing is successful, the BESS in a faulty phase is reconnected to the distribution system after checking the voltage and frequency in the steady state. If not, the recloser is locked out. Because the proposed technique maintains the power supply to healthy phase by BESS, this technique can be only applied to single phase load. The $\alpha$ to judge a fault occurrence is dependent on the system conditions and it is set to 500 in the simulations. $\beta_{\text {frequency }}, \beta_{\text {voltage }}$ and $\beta_{\text {angle }}$ for synchronism checking are decided based on [20] regardless of the system conditions. $\beta_{\text {frequency }}, \beta_{\text {voltage }}$, and $\beta_{\text {angle }}$ are set to $0.2 \mathrm{~Hz}, 5 \%$, and 15 degrees in the simulations, respectively.

Figure 3 shows the state transition of each circuit breaker according to the proposed reclosing process. ' $\mathrm{S} 1$ ' means the state of recloser. 'S2' and 'S3' mean the state of breaker for connection of BESS at fault and healthy phase, respectively. Also, ' 1 ' and ' 0 ' mean the close and open state, respectively. The state of recloser and the breaker at faulty phase transit to ' 1 ' or ' 0 ' by the proposed reclosing process, however, the state of breaker at healthy phase maintains ' 1 '. The state diagram used in the sequential machines is a directed graph that allow us to visualize the sequence of states. For each combination of current state and input, the next state in the process is shown by the state diagram [21].

Figure 4 shows the state diagram for all the events and their transitions in proposed reclosing process. The signal for state transition in Fig. 4 mean the 'S1', 'S2', and 'S3'. The initial state is (1)Normal. The change of ' $\mathrm{S} 1$ ', 'S2', and 'S3' after fault occurrence cause the transition to next state. When the process remains in state (3) after $15 \mathrm{~s}$, the process enters into state (5) and the reclosing is lockout. The sequence of state transition in case of Fig. 3a, b is (1)-(2)-(3)(4)-(6)-(1) and (1)-(2)-(3)-(4)-(3)-(4)-(6)-(1), respectively. In case of permanent fault shown in Fig. 3(c), the sequence of state transition is (1)-(2)-(3)-(4)-(3)-(4)-(3)-(5).

Fig. 2 Flowchart of new reclosing technique 


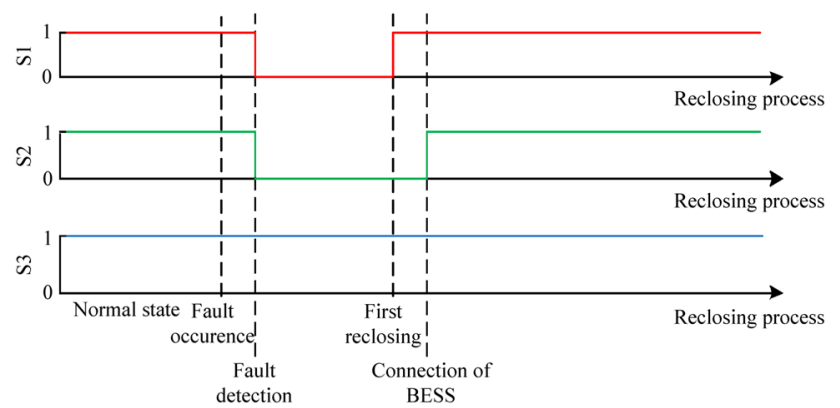

(a) Success at first reclosing

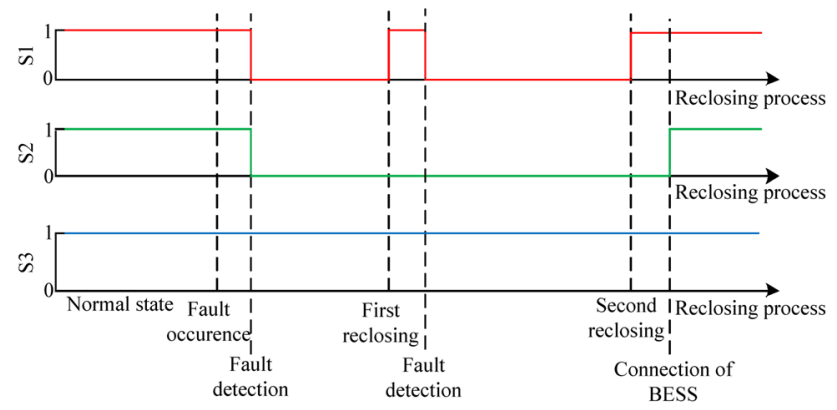

(b) Success at second reclosing

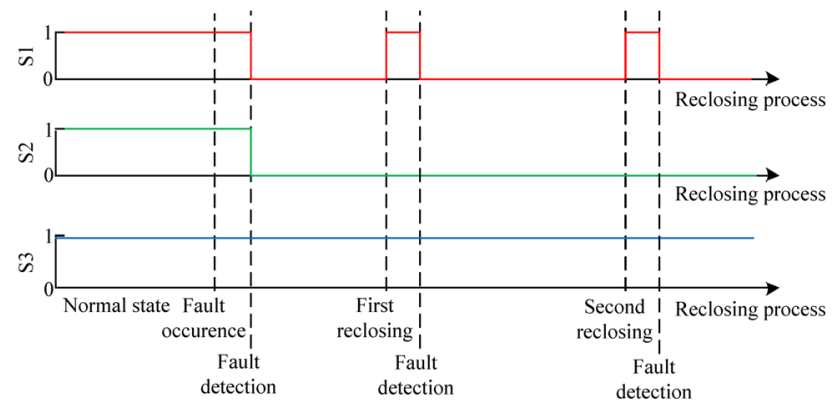

(c) Permanent fault

Fig. 3 State transition of each breaker at proposed reclosing process

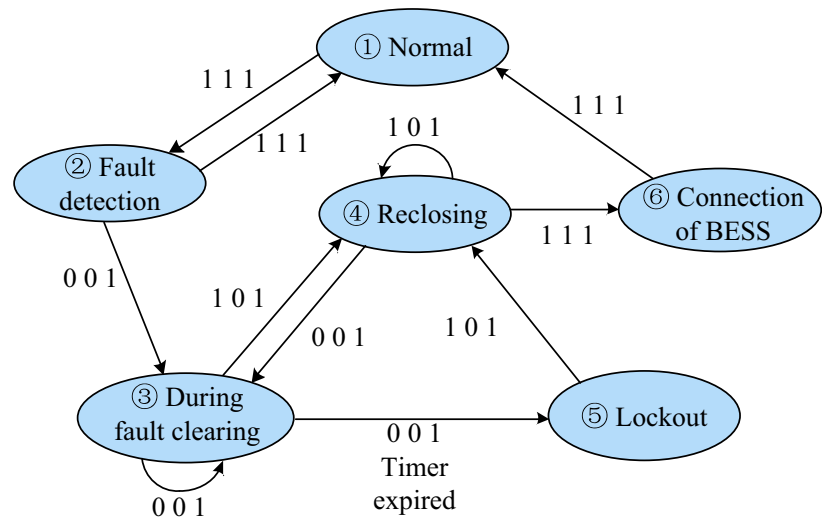

Fig. 4 State diagram for all events and their transitions in proposed reclosing process

\section{Simulations and discussion}

\subsection{System model}

Figure 5 shows a system model to test the proposed reclosing scheme. The type and length of Line1 and Line2 are ACSR $95 \mathrm{~mm}^{2}$ and $10 \mathrm{~km}$, respectively. The capacities of the BESS and the load are $1000 \mathrm{kWh}$ and $3000 \mathrm{~kW}$, respectively. All of loads are single phase loads.

As shown in Fig. 5, the BESS is assumed to have a large enough capacity such that it does not finish discharging during its operation as a UPS under fault conditions.

The BESS and the distribution system are modeled by using EMTP/ATPDraw [22]. The proposed algorithm is implemented by using EMTP/MODELS. The proposed algorithm is based on 120 samples/cycle and hence it is possible to implement the real-time operation using hardware.

\subsection{Simulation conditions}

Table 1 presents the simulation conditions to test the proposed reclosing scheme. Two transient fault cases (cases 1 and 2) are simulated. And one permanent fault case (case 3 ) is simulated. Cases 1 and 2 are the condition to verify the first and second reclosing attempts, respectively. From 0 to $1 \mathrm{~s}$, the BESS is charged. If the BESS has large capacity to serve the power to the load of the healthy phases, there's no difference at fault conditions whether it was in the charging state of fully charged. Therefore, the fault is occurred after fully charged at all of cases.

Fault conditions are as follows:

1) Fault type: Single line-to-ground faults of phase B.

2) Fault resistance: $1 \Omega$.

3) Fault location: $50 \%$ of line 2 .

For reduction of the simulation time, the dead time for the second reclosing is changed to $4 \mathrm{~s}$ instead of $15 \mathrm{~s}$.

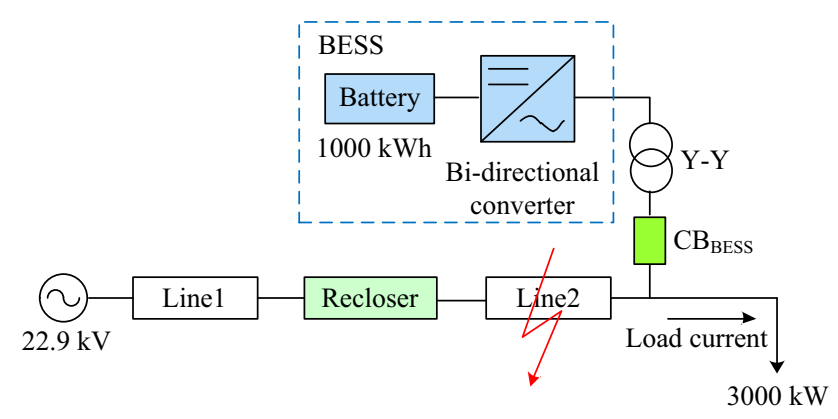

Fig. 5 System model to verify proposed reclosing technique 
Table 1 Simulation conditions

\begin{tabular}{llll}
\hline Case & Fault occurrence & Fault clearing & Description \\
\hline 1 & 1.2 & 1.3 & Transient fault \\
2 & 1.2 & 4.0 & Transient fault \\
3 & 1.2 & - & Permanent fault \\
\hline
\end{tabular}

\subsection{Simulation results and discussion}

\subsubsection{Case 1}

Figures 6 and 7 show the root-mean-square (RMS) waveforms of load current at fault occurrence and first reclosing instant in case 1, respectively. The measuring point of load current is presented in Fig. 5. The fault occurs at $1.2 \mathrm{~s}$ and the recloser is tripped at $1.25 \mathrm{~s}$. The load current during fault is small than rated current because the current from both BESS at faulty phase and main sources flows to the fault point not load. According to the proposed algorithm, after tripping of recloser, the BESS supplies power in healthy phases. i.e., phase A (red line) and phase $\mathrm{C}$ (blue line), but not in a faulty phase i.e., phase B (green line). The reclosing is performed at $1.757 \mathrm{~s}$, and the BESS in a faulty phase is reconnected at $1.806 \mathrm{~s}$ after successful reclosing. No transient phenomena occur after reconnection of the BESS in a faulty phase.

Figure 8 shows the state and open/close signals of the recloser and the BESS in case 1. The signal of the recloser is changed to " 0 " after the recloser trips due to fault occurrence and " 1 " at the reclosing instant. The signal of the BESS in a healthy phase does not change in the proposed algorithm. The signal of the BESS in a faulty phase is changed to " 0 " after fault occurrence and " 1 " after successful reclosing.

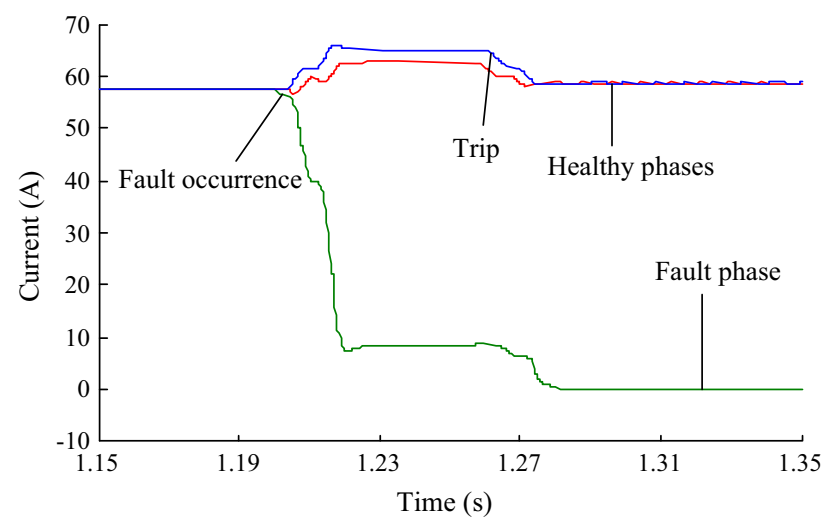

Fig. 6 Load current at fault occurrence instant in case 1

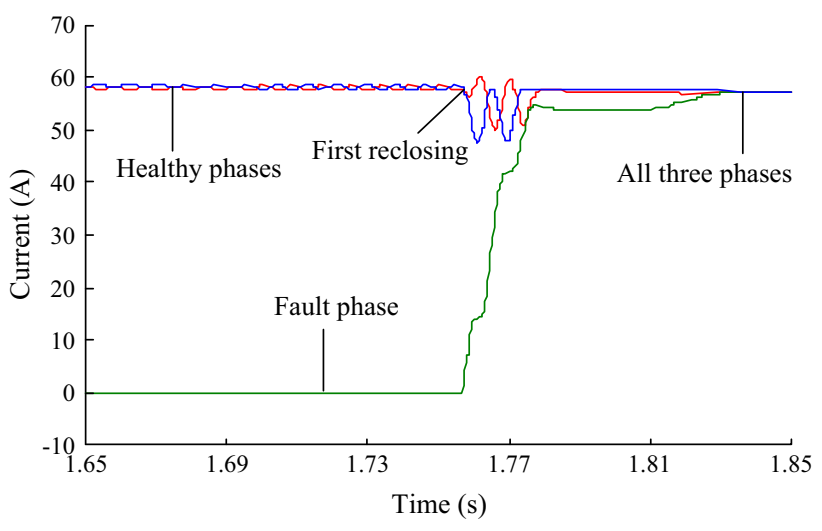

Fig. 7 Load current at first reclosing instant in case 1
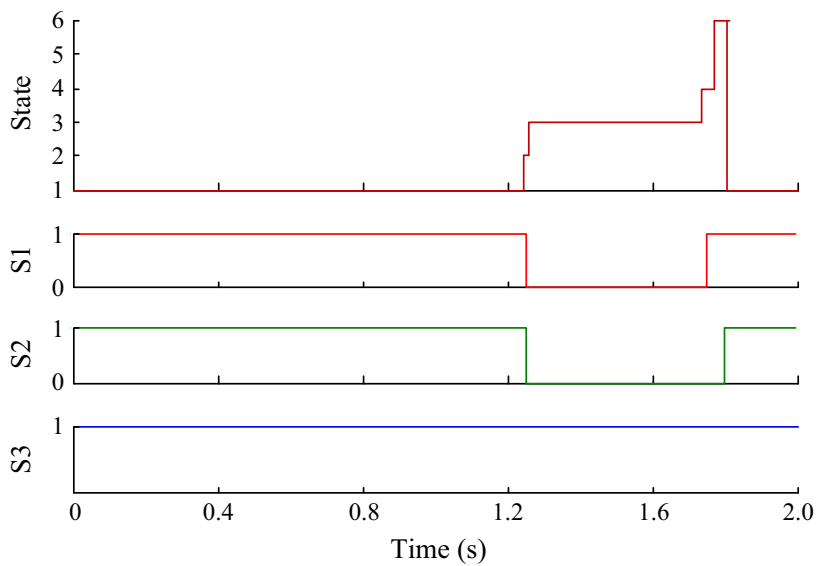

Fig. 8 State and open/close signal of recloser and BESS in case 1

\subsubsection{Case 2}

The waveform of load current at fault occurrence instant in case 2 is equal to Fig. 6. Figures 9 and 10 show the RMS waveforms of the load current at first and second reclosing instant in case 2, respectively. As shown in Figs. 6 and 9, the healthy phase has a steady state current because the BESS supplies the power to the healthy phase by the

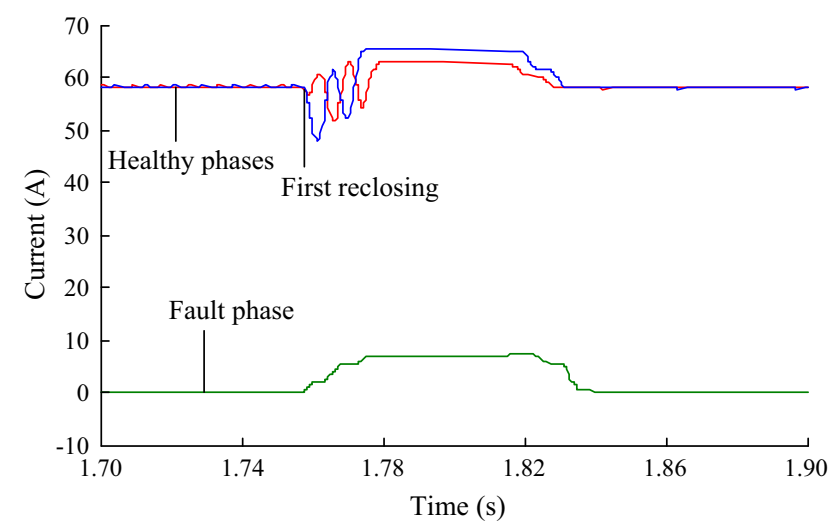

Fig. 9 Load current at first reclosing instant in case 2 


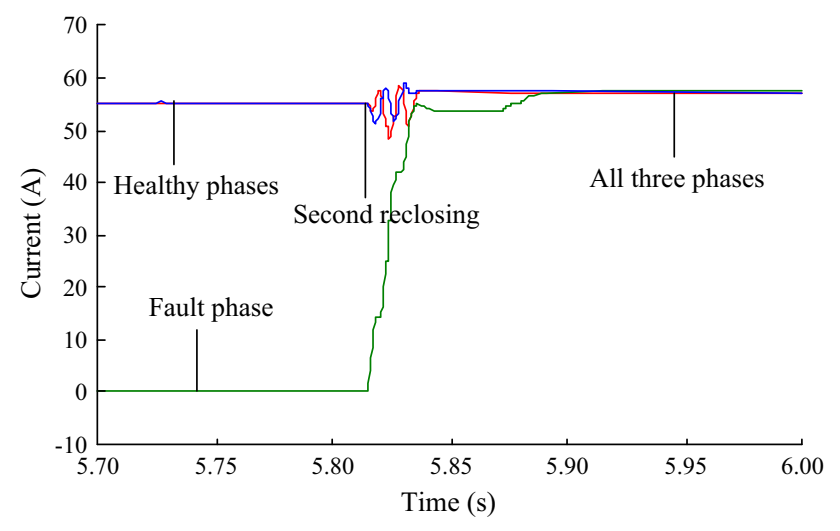

Fig. 10 Load current at second reclosing instant in case 2

proposed algorithm. The first reclosing is performed at $1.757 \mathrm{~s}$; however, it fails, and the current in a faulty phase is zero again after tripping of recloser until the second reclosing attempt. According to the proposed algorithm, the second reclosing is attemped at $5.815 \mathrm{~s}$, and the BESS in a faulty phase is reconnected at $5.865 \mathrm{~s}$. As in the simulation results for case 1 , no transient phenomena occur after reconnection of the BESS in a faulty phase.

Figure 11 shows the state and open/close signals of the recloser and the BESS in case 2. After the fault occurrence, the signal of the recloser and the BESS in a faulty phase is changed to " 0 " for the opening operation. The signal of recloser is changed to " 1 " for the first reclosing attempt; however, it is changed to " 0 " once again because of unsuccessful reclosing. In this step, the signal of the BESS in a faulty phase remains " 0 ". The signal of the recloser is changed to " 1 " for the second reclosing attempt, and the signal of the BESS in a faulty phase is changed to "1" after the successful second reclosing. The signal of the BESS in a healthy phase does not change during the reclosing process.
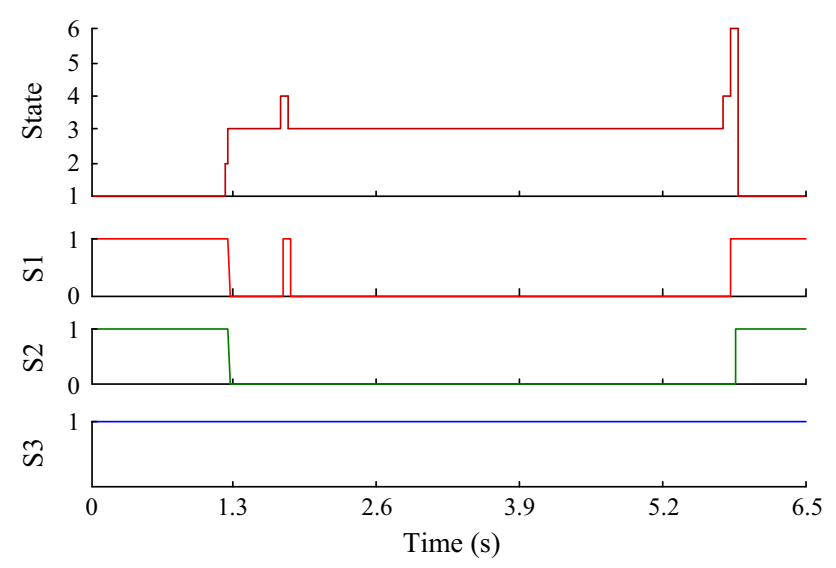

Fig. 11 State and open/close signal of recloser and BESS in case 2

\subsubsection{Case 3}

The waveforms of load current at fault occurrence and first reclosing instant in case 3 are equal to Figs. 6 and 9, respectively. Figure 12 shows the RMS waveforms of the load current at the second reclosing attempt in case 3 . The first and second reclosing attempts are performed according to the proposed algorithm; however, it fails, and so the current in a faulty phase is zero during the dead time. However, the normal current is supplied to the healthy phases by the BESS during the dead time and after lockout.

Figure 13 shows the state and open/close signals of the recloser and the BESS in case 3. The signal of the BESS in a healthy phase does not change during the reclosing process, and the signal in a faulty phase remains " 0 " after the fault occurrence because of unsuccessful reclosing. The signal of the recloser is changed to " 1 " during the reclosing attempts; however, it is changed to " 0 " again due to the permanent fault.

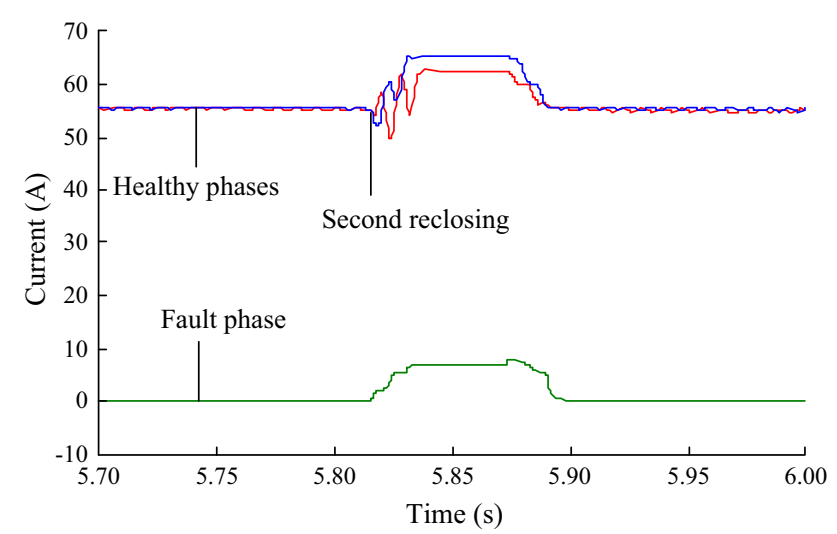

Fig. 12 Load current at second reclosing instant in case 3

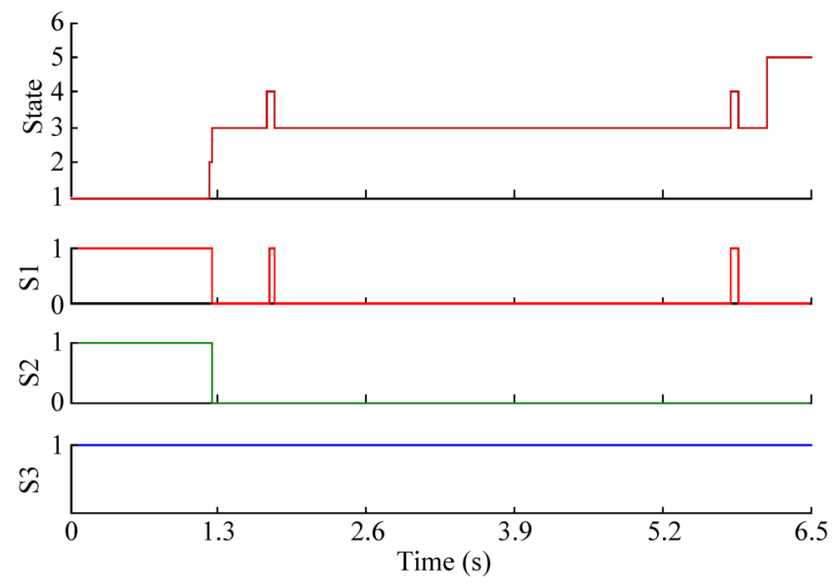

Fig. 13 State and open/close signal of recloser and BESS in case 3 


\subsection{Reclosing and reliability}

Synchronism checking might lead complicated procedure and malfunction. Therefore, the individual component as well as the whole system reliability should be considered. Synchronism checking relays have been produced by several companies and applied in the field. In particular, synchronism checking has been used in the reclosing of transmission lines, and no malfunction in synchronism checking has been reported. Also, with the development of digital signal processing technology, it is possible to accurately obtain the differences in voltage magnitude, frequency, and phase angle between two points. Therefore, this paper does not consider the reclosing failure due to the synchronism checking problems. The conventional distribution systems do not consider synchronism checking in reclosing procedure. If the BESS is disconnected from distribution system during fault, the BESS cannot be used for the UPS. In order to increase the utilization of BESS, the BESS should be connected during a fault, so the synchronism checking must be considered as discussed in introduction. The outage time of faulty phase will be increased due to extra time for synchronism checking. However, the extra time for synchronism checking is actually very short due to a development of digital signal technology. In [23], a time delay of synchronism relay using in power networks is specified. Estabilization time of synchronism relay signals is $30 \mathrm{~ms}$. Time for action of output unit of the synchronism relay is $30 \mathrm{~ms}$. Time set in the synchronism relay for checking depends on the setting of operator, which has usually a delay of $100 \mathrm{~ms}$ [23]. Therefore, the closing time delay is usually $160 \mathrm{~ms}$, i.e. about 10 cycles at $60 \mathrm{~Hz}$. In our algorithm, the normal power is supplied to the load by BESS after opening of CB. After that, the time delay for synchronism checking between source and load sides is counted. Therefore, in the simulation results, the reclosing is performed within $1 / 2$ cycles after fixed dead time ( 0.5 or $15 \mathrm{~s})$. This is very short time delay. In other words, the increase of outage time of faulty phase at the proposed scheme will be very short comparing with the conventional reclosing scheme. In summary, by applying proposed reclosing scheme, the interruptions of healthy phases will be prevented and hence the reliability will improve. Also, the increase of outage time of faulty phase will not affect to the reliability.

The use of a recloser or breaker with a reclosing relay at the substation, significantly reduces the number of sustained interruptions to a customer (SAIFI), the total duration of interruptions to the average customer (SAIDI) and the number of momentary interruptions (MAIFI). Single phase tripping is an option that utilities can utilize with modern high technology recloser. Since the vast majority of faults on distribution systems are line to ground, it makes sense to utilize the inherent capability of the recloser to operate in a single phase mode and thus reduce interruptions to customers on the other 2 phases [24]. The previous works between reclosing and reliability have not been studied on the similar reclosing operating mechanism with proposed reclosing method. However, the power supply to healthy phase by BESS to prevent the interruptions is similar with single phase reclosing. In [25], single phase reclosing yields an approximate $11 \% \sim 12 \%, 12 \%$, and $16 \%$ improvement in SAIDI, SAIFI, and MAIFI over a comparable system with three phase reclosing, respectively. Based on these results, we can expect the reliability improvement by proposed reclosing method. To perform the quantitative analysis of reliability, we will perform the reliability study considering the proposed reclosing method and system configuration.

\section{Conclusion}

This paper proposes a reclosing scheme using synchronism checking that considers the BESS in a distribution system. It discusses how the effects of the BESS in reclosing differ according to the BESS's purpose of use, and this paper deals with the BESS as UPS among several purposes. The proposed reclosing technique classifies the fault and healthy phases based on the fault current from utility, and so the BESS can keep the power service in the healthy phase. To minimize the effect in a healthy phase at the reclosing instant, this paper adopts synchronism checking between the main source side and load side.

To verify the proposed reclosing technique, this paper models the distribution system, BESS, and proposed algorithm using EMTP/ATPDraw and performs the various simulations according to the fault clearing time. From the simulation results, regardless of the fault clearing time, we can conclude that the reclosing can successfully be performed by the proposed reclosing technique and the BESS in a healthy phase can be operated as UPS.

Open Access This article is distributed under the terms of the Creative Commons Attribution 4.0 International License (http:// creativecommons.org/licenses/by/4.0/), which permits unrestricted use, distribution, and reproduction in any medium, provided you give appropriate credit to the original author(s) and the source, provide a link to the Creative Commons license, and indicate if changes were made.

\section{References}

[1] Liu J, Wen J, Yao W et al (2016) Solution to short-term frequency response of wind farms by using energy storage systems. IET Renew Power Gener 10(5):669-678 
[2] Zhou H, Bhattacharya T, Tran D et al (2011) Composite energy storage system involving battery and ultracapacitor with dynamic energy management in microgrid applications. IEEE Trans Power Electron 26(3):923-930

[3] Guerrero JM, Loh PC, Lee TL et al (2013) Advanced control architectures for intelligent microgrids Part II: power quality, energy storage, and AC/DC microgrids. IEEE Trans Ind Electron 60(4): 1263-1270

[4] Zhao H, Wu Q, Wang C et al (2015) Fuzzy logic based coordinated control of battery energy storage system and dispatchable distributed generation for microgrid. J Modern Power Syst Clean Energy 3(3):422-428

[5] Xu G, Xu L, Yao L (2013) Wind turbines output power smoothing using embedded energy storage systems. J Modern Power Syst Clean Energy 1(1):49-57

[6] Wang D, Ge S, Jia H et al (2014) A demand response and battery storage coordination algorithm for providing microgrid tie-line smoothing services. IEEE Trans Sustain Energy $5(2): 476-486$

[7] Xi X, Sioshansi R, Marano V (2014) A stochastic dynamic programming model for co-optimization of distributed energy storage. Energy Syst 5(3):475-505

[8] Brekken TKA, Yokochi A, Jouanne AV et al (2011) Optimal energy storage sizing and control for wind power applications. IEEE Tran Sustain Energy 2(1):69-77

[9] Xu Y, Singh C (2014) Power system reliability impact of energy storage integration with intelligent operation strategy. IEEE Trans Smart Grid 5(2):1129-1137

[10] Wang P, Gao Z, Bertling L (2012) Operational adequacy studies of power systems with wind farms and energy storages. IEEE Trans Power Syst 27(4):2377-2384

[11] Hadjipaschalis I, Poullikkas A, Efthimiou V (2009) Overview of current and future energy storage technologies for electric power applications. Renew Sustain Energy Rev 13(6-7):1513-1522

[12] Li X, Hui D, Lai X (2013) Battery energy storage station (BESS)-based smoothing control of photovoltaic (PV) and wind power generation fluctuations. IEEE Trans Sustain Energy $4(2): 464-473$

[13] Serban I, Marinescu C (2014) Control strategy of three-phase battery energy storage systems for frequency support in microgrids and with uninterrupted supply of local loads. IEEE Trans Power Electron 29(9):5010-5020

[14] Seo HC (2017) New adaptive reclosing technique using secondorder difference of THD in distribution system with BESS used as uninterruptible power supply. Int J Electr Power Energy Syst 90:315-322

[15] Seo HC (2017) New configuration and novel reclosing procedure of distribution system for utilization of BESS as UPS in smart grid. Sustainability 9(4):507
[16] Seo HC (2016) New reclosing technique in distribution system with battery energy storage system. J Korean Inst Illum Electr Install Eng 30(1):21-27

[17] Yang Y, Li H, Aichhorn A et al (2014) Sizing strategy of distributed battery storage system with high penetration of photovoltaic for voltage regulation and peak load shaving. IEEE Trans Smart Grid 5(2):982-991

[18] Shi D, Sharma RK (2013) Adaptive control of energy storage for voltage regulation in distribution system. In: Proceedings of international conference on smart energy grid engineering, Oshawa, ON, Canada, 28-30 Aug 2013, 7pp

[19] Rahimi A, Zarghami M, Vaziri M et al (2013) A simple and effective approach for peak load shaving using battery storage systems. In: Proceedings of North American power symposium (NAPS), Manhattan, KS, USA, 22-24 Sept 2013, 5pp

[20] KEPCO (2015) Technical standard for interconnecting distributed generation with distribution system. Korea

[21] Kim CH, Heo JY, Aggarwal RK (2015) An enhanced zone 3 algorithm of a distance relay using transient components and state diagram. IEEE Trans Power Deliv 20(1):39-46

[22] Kim JH, Lee SJ, Kim ES et al (2014) Modeling of battery for EV using EMTP/ATPDraw. J Electr Eng Technol 9(1):98-105

[23] Multilin GE (2007) Synchronism check relay instruction manual

[24] Application NOTE (2010) The effect of loop reconfiguration and single phase tripping on distribution system reliability. $\mathrm{ABB}$ Inc, Lake Maryu

[25] Goodin RE, Fahey TS, Hanson A (1999) Distribution reliability using reclosers and sectionalisers. ABB Inc, Lake Maryu

Hun-Chul SEO received his B.S, M.S, and Ph.D degrees from Sungkyunkwan University, Korea, 2004, 2006, and 2013, respectively. He worked for Korea Electrical Engineering \& Science Institute, Seoul, Korea, as a researcher in power system division from 2006 to 2009 . He was a post-doctoral fellow in the dept. of electrical engineering, Yeungnam University, Korea, from Sep. 2013 to Jan. 2014. From Mar. 2014, he is an assistant professor with the School of IT Engineering at Yonam Institute of Digital Technology, Korea. His research interests include power system transients, protection and stability.

Sang-Bong RHEE received his B.S, M.S, and Ph.D degrees from Hanyang University, Korea, in 1994, 1999, and 2004, respectively. He was a research professor in the School of Electrical and Computer Engineering, Sungkyunkwan University, Korea. Currently, he is an assistant professor with the dept. of electrical engineering at Yeungnam University, Korea. His research interests include distribution system control and operation, and artificial intelligence applications to power system protection. 